\title{
Multi-Objective Evolutionary Programming for Static VAR Compensator (SVC) in Power System Considering Contingencies (N-m)
}

\author{
Nor Rul Hasma Abdullah', Mahaletchumi A P Morgan ${ }^{2}$, Mahfuzah Mustafa ${ }^{3}, \operatorname{Rosdiyana~Samad}^{4}$, \\ Dwi Pebrianti \\ Faculty of Electrical \& Electronics Engineering, Universiti Malaysia Pahang, Pahang, Malaysia
}

\begin{tabular}{|c|c|}
\hline Article Info & ABSTRACT \\
\hline Article history: & Static VAR Compensators (SVCs) is a Flexible Alternating Current \\
\hline Received Dec 21, 2017 & Transmission System (FACTS) device that can control the power flow in \\
\hline Revised Jan 22, 2018 & the midpoint of interconnection line or in load areas. This device is capable \\
\hline Accepted Feb 7, 2018 & $\begin{array}{l}\text { of minimizing the overall system losses and concurrently improves the } \\
\text { voltage stability. A line index, namely SVSI becomes indicator for the }\end{array}$ \\
\hline Keyword: & $\begin{array}{l}\text { placement of } S V C \text { and the parameters of } S V C \text { are tuned by using the mult1- } \\
\text { objective evolutionary programming technique, effectively able to control the }\end{array}$ \\
\hline SVC & power. The algorithm was tested on IEEE-30 Bus Reliability Test System \\
\hline FACTS & (RTS). Comparative studies were conducted based on the performance of \\
\hline MOEP & $\mathrm{g}$ for installations in power $\mathrm{s}$ \\
\hline
\end{tabular}

Multi Objective Optimization

SVSI

Transmission Losses

$\mathrm{N}-\mathrm{m}$ Contingencies

Copyright $(0) 2018$ Institute of Advanced Engineering and Science. All rights reserved.

\section{Corresponding Author:}

Nor Rul Hasma Abdullah,

Faculty of Electrical \& Electronics Engineering,

Universiti Malaysia Pahang,

Cawangan Pekan, 26600 Pekan, Pahang, Malaysia.

Email: hasma@ump.edu.my

\section{INTRODUCTION}

Nowadays, electrical power system becoming more stressed and difficult to operate due to increasing electricity demand and also restrictions on the construction of new lines [1]. This causes greater losses in the power system network. Besides that, due to constraints, voltage and stability limits work below their thermal rating. Furthermore, substitution of new transmission line cost very high to take increased load demand on the power system. Hence, to overcome inefficient utilization of transmission system infrastructure, power electronics have been developed the flexible AC transmission system (FACTS) devices [2]. FACTS devices used to control the main parameter, namely, steady state and transient stabilities of a complex power system and voltage [3]. This parameter influences the AC power transmission [4]. Moreover, this device act as ideal switch that is controllable and also sustain high levels of tension and power. Normally, FACTS device can be divided into two, namely, the Thyristor-Controlled FACTS devices and Voltage Sourced Converter (VSC)-based FACTS devices. The Thyristor-Controlled FACTS devices are included SVC and TCSC while VSC based FACTS devices are including IPFC and SSSC, shunt devices like STATCOM. In power flow studies Thyristor-Controlled FACTS devices act as controllable impedance, but VSC-based FACTS devices act as controllable sources which is more complex [5][6].

Recently, researcher has been developed algorithm incorporating with the FACTS device in order to solve the problem. The techniques are included, Genetic Algorithm (GA), Bee Algorithm (BA) and Particle 
Swarm Intelligence (PSO) [7]-[9]. In brief, the FACTS device used sensitivity based method to determine the optimal placement of FACTS devices for voltage stability improvement. In 2001, Padhy proposed a method that incorporates with FACTS to overcome optimal reactive power dispatch problem. The proposed method is a new hybrid model for optimal power flow. The fuzzy variables of the proposed method are including generation outputs, cost of generation and load demands [6]. Besides that, Chung and Li suggested an improved GA to overcome problems regarding optimal reactive power dispatch by using FACTS device. There are two types of FACTS device have been used to control power flow. It is included TCPS and TCSC. The developed algorithm that is GA joined with AC power flow in order to reduce the total generation fuel cost and to maintain the power flow within the constraints [10]. Similarly, in 2006, Shao and Vittal proposed a linear programming (LP) with a FACTS device for solving Optimal reactive power dispatch problem that is lightening overloads in transmission line and voltage violations due to contingency. The developed algorithm applied to the New England 39-bus system and the WECC 179-bus system [11].

This paper presents a new approach for installation of FACTS based SVC on Multi-Objective Evolutionary Programming (MOEP) optimization technique considering multi-contingencies $(N-m)$ occurrence in the system. The proposed technique determines the optimum sizing of Static VAR Compensator (SVC) in order to reduce the total transmission loss in the system. Static Voltage Stability Index (SVSI) is used as the tool to indicate the SVC's location to be installed into the power system network. The SVSI and transmission loss minimization was used as the objective function in the system. A computer program was written in MATLAB and the proposed techniques were tested on the IEEE 30-bus RTS. In addition, comparative studies are conducted by comparing the results with Multi-Objective Artificial Immune System (MOAIS). An algorithm to apply such multi-objective optimization has been formulated based on the same non-dominated sorting concept implemented in non-dominated sorting genetic algorithm (NSGA-II). In addition, a program is also developed to obtain best compromise solution in a power system.

\section{MULTI OBJECTIVE OPTIMIZATION}

Multi-objective optimization is a process to find the value of the variables that minimize the objective function namely SVSI and transmission loss while the system is operating within its constraint limit. Multi-objective problems are more difficult to solve compared to the single objective since there is no unique solution. Instead of one optimal resolution, the implementation of multi-objective can give a set of optimal solutions. These optimal solutions are known as Pareto-optimal solutions. The set of all feasible nondominated solution is referred to as the Pareto optimal set, and for a given Pareto optimal set, the corresponding objective function values in the objective space is called the Pareto front. The multi objective optimization problem is specified as follows[12]:

$$
\begin{array}{cll}
\text { Min / maximization } & : & F(x)=\left[f_{1}(x), f_{2}(x), f_{3}(x) \ldots \ldots . . f_{k}(x)\right] \\
\text { Subjected to } & : & g_{i}(x) \leq 0 \text { where } \mathrm{i}=1,2,3 \ldots . . \\
& : & h_{j}(x)=0 \text { where } \mathrm{k}=1,2,3 \ldots \ldots . j
\end{array}
$$

Where $F(x)$ is objective, $f_{1}(x), f_{2}(x), f_{3}(x) \ldots \ldots . f_{k}(x)$ are the objective function, $x$ is the vector of dependent variable, $g$ is the equality constraints and h is the inequality constraint.

The FACTS device installed on the weak buses and heavily loaded areas in order to reduce the stress condition in the system. The locations of SVCs devices indicated using the SVSI technique that operates at same operating conditions in the power system network. When the load flow program was run, stability indices are calculated and the system identified the lin with the highest SVSI fo the installation of FACTS device. Finally, MOEP technique was used to identify the optimal size of the SVC. The process of installation considered the occurrence of generator outages.

\subsection{Static Voltage Stability Index (SVSI)}

SVSI which is a line-based voltage stability index was developed by [13]. This index used in the voltage stability analysis as an indicator of the voltage stability condition of a system. The voltage stability condition of all lines in power system could be assessed using this index, which could predict the occurrence of voltage collapse in a system. SVSI was formulated by deriving the voltage quadratic equation for a general two-bus system at the receiving end. $S V S I_{j i}$ can be defined as shown in Equation (2) for the two-bus system.

$$
S V S I_{j i}=\frac{2 \sqrt{\left(X_{j i}^{2}+R_{j i}^{2}\right)\left(P_{j i}^{2}+Q_{j i}^{2}\right)}}{\left.|| V_{i}\right|^{2}-2 X_{j i} Q_{j i}-2 R_{j i} P_{j i} \mid}
$$


Where the active power and reactive power are $P_{j i}$ and $Q_{j i}$. The line resistance and reactance are $R_{j i}$ and $X_{j i}$. The voltage magnitude and angle are $|\mathrm{V}|$ and $\delta$. The subscript $i$ and $j$ denote variables associated with bus $i$ and bus $j$. SVSI indicated the steady state voltage stability of the line. If the SVSI is less than one, there are solutions and the system is stable. If the SVSI is larger than one, there is no solution and the system becomes unstable or steady state voltage collapse occurs in the system.

\subsection{Minimization of transmission loss as objective function}

Another objective function considered in the proposed method is minimizing the transmission power losses in the transmission network, while satisfying a set of physical and operation, subjected to a set of equality and inequality constraints in the power system [14].

The mathematical equation of transmission loss can be written as

$$
\min f_{p}=\sum_{k \in N_{E}} P_{k_{\text {Loss }}}(V, \theta)=\sum_{\substack{k \in N_{E} \\ k=(i, j)}} g_{k}\left(V_{i}^{2}+V_{j}^{2}-2 V_{i} V_{j} \cos \theta_{i j}\right)
$$

Subject to:-

$$
h_{Q i}=Q_{G i}-Q_{D i}-V_{i} \sum_{j \in N_{i}} V_{j}\left(G_{i j} \sin \theta_{i j}-B_{i j} \cos \theta_{i j}\right)=0, i \in N_{P Q}
$$

Subject to the constraint of equality in reactive and active power balance

$$
\begin{aligned}
& Q_{i}-Q_{G i}+Q_{D i}=0, Q_{i}=Q_{G i}-Q_{D i}-V_{i} \sum_{j \in N_{i}} V_{j}\left(G_{i j} \sin \theta_{i j}-B_{i j} \cos \theta_{i j}\right)=0, \quad i \in N_{P Q} \\
& P_{i}-P_{G i}+P_{D i}=0, P_{i}=P_{G i}-P_{D i}-V_{i} \sum_{j \in N_{i}} V_{j}\left(G_{i j} \cos \theta_{i j}-B_{i j} \sin \theta_{i j}\right)=0, \quad i \in N_{B-1}
\end{aligned}
$$

Hence, inequality constraints on control variable limits; generator power reactive capability limits, generator power active capability limits, and voltage constraints are given by;

$$
\begin{aligned}
& Q_{G i_{\min }} \leq Q_{G i} \leq Q_{G i_{\max }} \quad i \in N_{G} \\
& Q_{c i_{\min }} \leq Q_{c i} \leq Q_{c i_{\max }} \quad i \in N_{c} \\
& P_{G i_{\min }} \leq P_{G i} \leq P_{G i_{\max }}, \quad i \in \text { Slackbus } \\
& V_{i_{\min }} \leq V_{i} \leq V_{i_{\max }} \quad i \in N_{B}
\end{aligned}
$$

where, $g_{k}$ is the conductance of branch $\mathrm{k}, n_{s}$ is the slack (reference) bus number; $N_{P Q}$ is $P Q$ bus number, $N_{P V}$ is $P V$ bus number, $N_{B}$ is the total number of buses, $N_{B-1}$ is the total buses excluding slack bus, $N_{c}$ is the possible reactive power source installation buses number, $N_{E}$ is the branch number, $N_{i}$ is the numbers of buses adjacent to bus $i$ including bus $i, \theta_{i j}$ is voltage angle different between bus $i$ and bus $j(\operatorname{rad}), Q_{i}$ and $Q_{j}$ are the reactive power on the sending and receiving buses; $Q_{G}$ is the generated reactive power, $V_{i}$ and $V_{j}$ are the voltage magnitude at the sending and receiving buses, $G_{i j}$ and $B_{i j}$ is the mutual conductance and subceptance between bus $i$ and bus $j$ and $P_{K_{\text {Loss }}}$ is the total active power loss in the system.

\section{MULTI-OBJECTIVE EVOLUTIONARY PROGRAMMING}

The MOEP mainly carried out six steps, namely, initialization, non-dominated sorting, crowding distance, mutation, combination and selection. The population is initialized to generate random number generation. In MOEP initialization is one of the important processes to produce first population termed as parents. Then, The population is sorted based on the non-domination. Each solution should be compared with every other solution in the population to find if it is dominated. Each solution assigned a fitness or rank equal to its non-domination level ( 1 is the best level, 2 is the next best level and so on). Furthermore, the first rank belongs to the most excellent non-dominated set in the population [15]. Once the non-domination sort is completed, the crowding distance is assigned. Crowding Distance also known as a fitness value of an individual. The purpose of crowding distance is to provide the diversity in the population [12]. Then, the individual solutions are sorted in descending order based on the magnitude of the crowding distance values. Subsequently, the process continued with the mutation process. The mutation operator changed its current value of a continuous variable to a neighboring value using Polynomial Probability Distribution and this is a basic procedure of any genetic operator [16]. The offspring produces from the mutation process are combined with the clone parent to undergo a selection process in order to identify the candidates have the chance to be transcribed in the following generation. The best individual from the offspring population will be selected 
according to a selection scheme in order to form the parent population for the following generation. The offspring is chosen using tournament scheme. Finally, the MOEP produces a set of Pareto optimal solution which one objective cannot be improved without sacrificing other objective. Therefore, from the Paretooptimal set of non-dominated solutions, the Best Compromise Solution (BCS) was selected for the decision maker as the BCS will decide the best solution in between both objective functions [17].

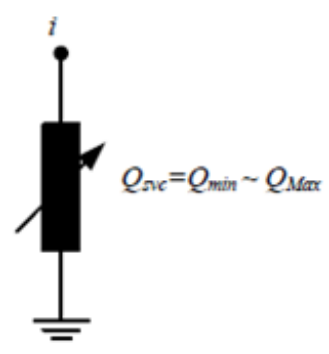

Figure 1. SVC Model

\section{STATIC VAR COMPENSATOR (SVC)}

Nowadays, SVC is the most popular FACTS devices which are used to solve optimal reactive power problem (ORPD). Furthermore, SVC not only generate reactive power but is also absorbing reactive power. SVC connected in parallel to transmission line where TCR located in parallel with capacitor bank [18]. Usually, SVC installed at the end of the transmission line or midpoint of transmission interconnections. Moreover, SVC is a three phase and shunt connected device. The main function of SVC is to improved voltage in weak transmission line.

The mathematical modelling of SVC considered in this study is shown in Figure 1. In recent years SVC has been used for reactive power support and to enhance voltage stability in the electrical power system network. Furthermore, the SVC can act as both inductive and capacitive compensation by absorbing releasing reactive power. Hence, it is modelled as ideal reactive power injections to perform the steady-state condition at bus $i$. The absorbed or injected power at bus $i$ in the system is represented by $Q_{s v c}$. The mathematical formulation of SVC constraint shown as

$$
\begin{gathered}
Q_{\min } \leq Q_{S V C} \leq Q_{\max } \\
-200 \mathrm{MVar} \leq \mathrm{Q}_{\mathrm{SVC}} \leq 200 \mathrm{MVar}
\end{gathered}
$$

\section{APPLICATION OF MOEP IN SVC DEVICE INSTALLATION}

MOEP involved initialization, non-dominated sorting, crowding distance, mutation, combination and selection. Transmission loss minimization and voltage stability were chosen as the objective function for the optimization process. The flow chart for the application of MOEP in SVC device installation is shown in Error! Reference source not found. Several inequality constraints are set in this study so as to achieve the optimal solution. Several generator outages namely generator at bus 11 and 13 were subjected into the system. The selections of outages are based on the most severe generator and in the system to maximize the performance of the system. There are two constraints assigned before the SVCs sizing is optimised. The constraints are; total loss to be less than the loss_set and voltage at the loaded bus higher than $V_{-}$set. The loss_set and $V \_s e t$ are the total loss and voltage at the loaded bus before the optimisation process was conducted. The following steps show the implementation of EP.

i. Set the generator outages.

ii. $\quad$ Set the loading factor, $\lambda$.

iii. $\quad$ Setting the location for SVC using SVSI index of stability.

iv. Set the ORPD constraints i.e. SVSI $\leq S V S I \_s e t$ and total loss $\leq$ loss_set as objective functions.

v. Generate random number i.e. $x_{1}, x_{2}, \ldots x_{5}$. Check for constraint violations. If constraints violated, go to step iv, otherwise go to step vi.

vi. $\quad$ Fill in population pool. Repeat step (ii) if pool was not full, otherwise continue to step (vii).

vii. Calculate the non-dominated solution for each individual in the population.

viii. Sort the entire population using front.

ix. $\quad$ Calculate the crowding distance for each front 
x. $\quad$ Mutate the parents $x_{1}, x_{2}, x_{3}, x_{4}$ and $x_{5}$ to generate offsprings.

xi. Assign $x_{1}, x_{2}, x_{3}, x_{4}$ and $x_{5}$ in the bus system data.

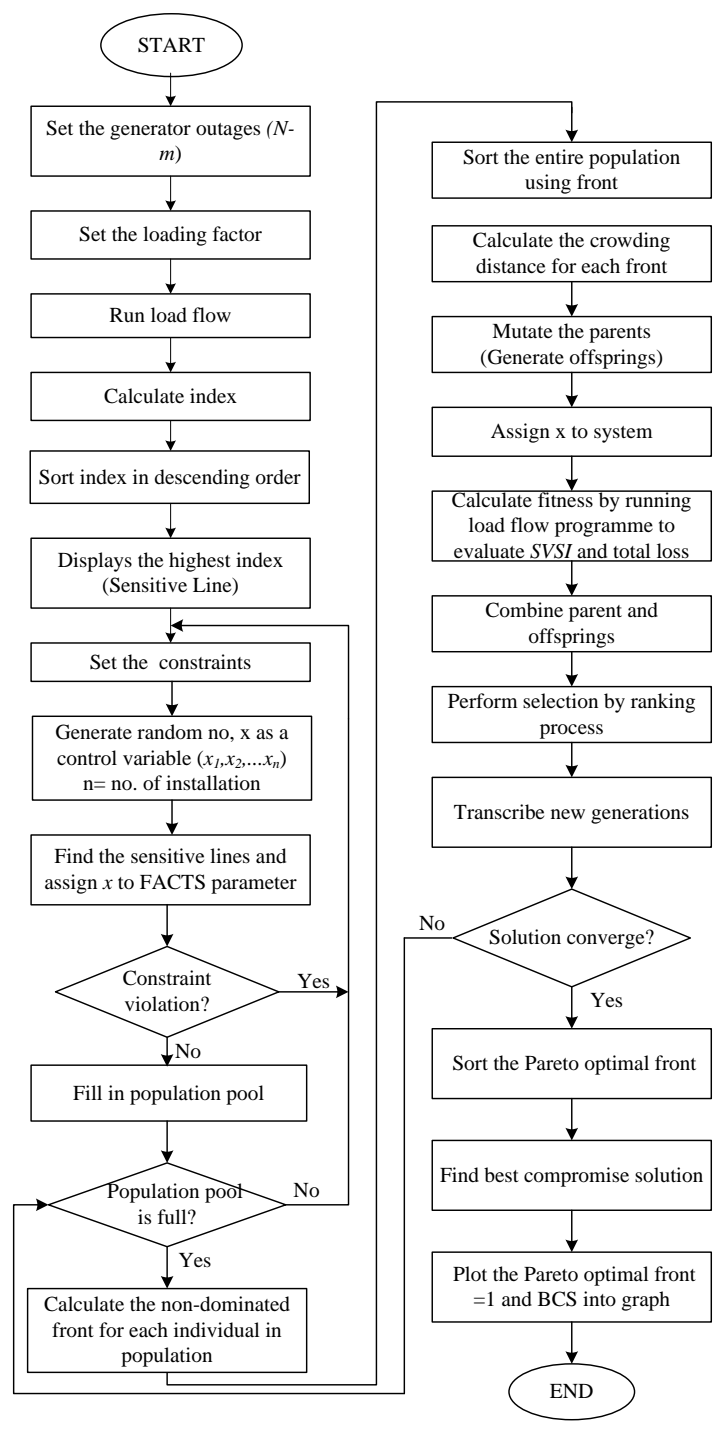

Figure 2. Flowchart for SVC installation using MOEP

xii. Calculate fitness by running load flow program to evaluate SVSI values and transmission loss values.

xiii. Combine parents and offspring (combination process).

xiv. Perform selection by tournament selection process from the combine data.

xv. Identify and transcribe new generations.

xvi. If solution is not converged, repeat step v to xii, otherwise go to step xvii.

xvii. Sort the Pareto optimal front.

xviii. Find the best compromise solution.

xix. Plot the Pareto optimal front and the best compromise solution into graph.

xx. Stop

\section{RESULTS AND ANALYSIS}

The results have been obtained from the developed algorithm for multi-objective evolutionary programming for SVC installation and sizing. The developed algorithm has been tested on the IEEE 30-Bus 
RTS. The SVC installation has been formed by considering multi-contingencies $(N-m)$; generator outages have been occurred in the system which are formulated with the objective of minimizing the SVSI and real power loss, respectively. For the studies, the population size selected is 200, mutation probability is 0.1 and distribution index for mutation is 20. Population size of 200 was chosen based on exhaustive experiment on various population sizes which revealed that 200 is the most suitable one. In this study, MOEP algorithm has been applied where both SVSI and transmission loss were optimized simultaneously. The developed algorithm has been tested with bus 26 subjected to a maximum loadability in the IEEE 30-bus RTS. The simulation results are tabulated in Table 1. The Pareto optimal fronts set are shown in Figure 2.

The diversity of the Pareto-optimal set over the trade-off surface for bus 26 is shown in this figure. It is observed that the proposed approach produces 200 Pareto-optimal solutions. Out of the solutions obtained, two non-dominated solutions that represent the best SVSI value and best transmission loss are given in Table 1. The best compromise solution of this method is also given in this table. It is observed that the SVSI and transmission loss values, reduce with respect to $\lambda$ after the implementation of MOEP in the system.

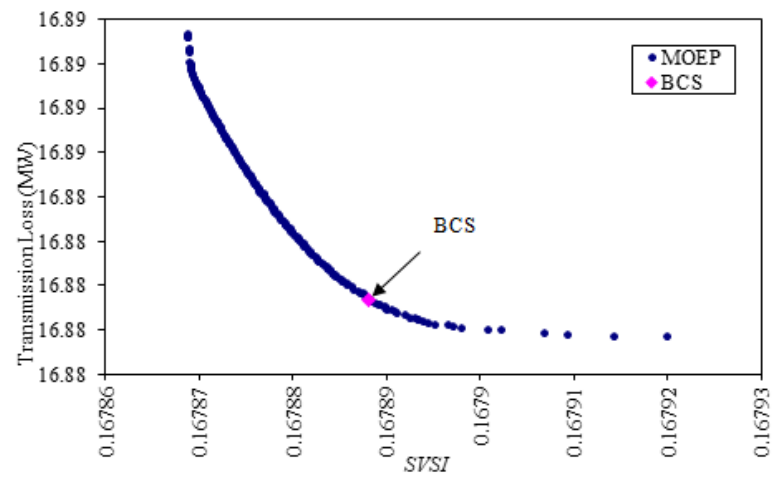

Figure 3. Pareto front for SVSI and transmission loss minimization obtained using MOEP for SVC sizing at bus 26

Table 1. Results for MOEP when bus 26 was reactively loa ded for $\lambda=30 \mathrm{MVAr}$

\begin{tabular}{ccccc}
\hline $\begin{array}{c}\text { Units } \\
\text { (in MVAr) }\end{array}$ & pre-SVC & $\begin{array}{c}\text { Solution at minimum } \\
\text { SVSI }\end{array}$ & $\begin{array}{c}\text { MOEP } \\
\text { Solution at minimum } \\
\text { Transmission Loss }\end{array}$ & $\begin{array}{c}\text { Best Compromise } \\
\text { Solution }\end{array}$ \\
\hline SVC $_{1}$ & Bus 26 & -3.2409 & -1.8782 & -1.9755 \\
SVC $_{2}$ & Bus 27 & -32.2077 & -30.0446 & -31.0392 \\
SVC $_{3}$ & Bus 25 & 20.0739 & 19.5343 & 19.0337 \\
SVC $_{4}$ & Bus 27 & -32.5618 & -33.4772 & -33.2473 \\
SVC $_{5}$ & Bus 5 & -27.4607 & -25.4652 & -27.8897 \\
SVSI & 0.5835 & 0.16787 & 0.16792 & 0.16789 \\
Transmission Loss & 28.0137 & 16.8913 & 16.8777 & 16.8794 \\
(in MW) & & & & \\
\hline
\end{tabular}

Table 2. Results for MOAIS when bus 26 was reactively loaded for $\lambda=30$ MVAr

\begin{tabular}{ccccc}
\hline $\begin{array}{c}\text { Units } \\
\text { (in MVAr) }\end{array}$ & pre-SVC & $\begin{array}{c}\text { Solution at minimum } \\
\text { SVSI }\end{array}$ & $\begin{array}{c}\text { MOAIS } \\
\text { Solution at minimum } \\
\text { Transmission Loss }\end{array}$ & $\begin{array}{c}\text { Best Compromise } \\
\text { Solution }\end{array}$ \\
\hline SVC $_{1}$ & Bus 26 & -9.0485 & -6.6835 & -7.0939 \\
SVC $_{2}$ & Bus 27 & -25.7690 & -25.4146 & -25.7839 \\
SVC $_{3}$ & Bus 25 & 10.7274 & 12.2215 & 11.9964 \\
SVC $_{4}$ & Bus 27 & 28.5779 & 27.3093 & 27.2783 \\
SVC $_{5}$ & Bus 5 & -26.5534 & -27.0564 & -27.1382 \\
SVSI & 0.5835 & 0.16790 & 0.16792 & 0.16791 \\
Transmission Loss & 28.0137 & 16.9335 & 16.9031 & 16.9066 \\
(in MW) & & & & \\
\hline
\end{tabular}

Table 3. Best Com prom ise Solution for SVC installation when bus 26 was reactively loa ded.

\begin{tabular}{cccc}
\hline Technique & $\begin{array}{c}\text { Non dominated } \\
\text { Solutions No. }\end{array}$ & SVSI & $\begin{array}{c}\text { Transmission Loss } \\
\text { (in MW) }\end{array}$ \\
\hline MOEP & 196 & 0.16789 & 16.8794 \\
MOAIS & 12 & 0.16791 & 16.9066 \\
\hline
\end{tabular}


It implies that the voltage stability has been improved. The best SVSI value is 0.16787 while the best transmission loss is $16.8777 \mathrm{MW}$. The best compromise solution is 0.16789 for SVSI and $16.8794 \mathrm{MW}$ for transmission loss. It is observed that the SVSI and transmission loss have been reduced with the implementation of MOAIS. It implies that the voltage stability has been improved. The best SVSI value is 0.16790 while the best transmission loss is $16.9031 \mathrm{MW}$. The best compromise solution is $0.16791 \mathrm{for}$ SVSI and 16.9066 MW for transmission loss.

The comparison result for the best compromise solution for different optimization technique using MOEP and MOAIS for the implementation of SVC is tabulated in Table 3. In this table, the results are verified from three aspects in terms of SVSI value, transmission loss and amount of non-dominated solutions. When the load is subjected to bus 26, it shows that only 12 non dominated solutions distributed along Pareto Front using MOAIS. Nevertheless, the MOEP has presented 196 non-dominated solutions along the Pareto Front, in which it gives more choices of selection for SVC installation size to improve SVSI and reduce the transmission loss in the system. As highlighted in the table, it is observed that MOEP outperformed MOAIS since MOEP managed to improve the SVSI value and transmission losses as compared to MOAIS in the system.

\section{CONCLUSION}

This chapter has presented multi-objective optimization techniques termed as MOEP in implementing the optimal sizing of the SVC installation scheme. The combination of SVSI and transmission loss minimization as objective function has been solved for the IEEE 30-bus RTS system with bus 26 subjected to loading condition. The Pareto-optimal front has been obtained in all schemes and the best compromise solution shows the promising results where MOEP and MOAIS successfully improved the SVSI value and reduced the transmission loss values in the system. Finally, the results obtained from the MOEP techniques were compared with MOAIS and it was found that MOEP outperformed MOAIS in all cases.

\section{ACKNOWLEDGEMENTS} RDU1703226.

The authors gratefully acknowledge the financial supports from Universiti Malaysia Pahang Grant,

\section{REFERENCES}

[1] V. K. Candrakar, et al., "Flexible Alternating Current Transmission System (FACTS) for Cost Effective and Reliable Transmission of Electrical Energy," National Power Engineering Conference (NPEC-07) , June 2007.

[2] R. K. Verma, et al., " Optimization Technique Based for Optimal Location of FACTS Devices," International Technique of Interdisciplinary Innovative Research \& Development, vol. 1, April 20171997.

[3] N.G. Hingorani and L. Gyugyi, " Understanding FACTS : Concepts and Technology of Flexible AC Transmission systems," IEEE Power Engineering Society, IEEE Press, 2001.

[4] N. G. Hingorani and L. Gyugyi, "Understanding FACTS: Concepts and Technology of Flexible AC Transmission Systems,"New York: IEEE Press, 2000.

[5] M. Eslami, et al., "Application of PSS and FACTS Devices for Intensification of Power System Stability", International Review of Electrical Engineering (IREE), vol. 5, pp. 552-570, April 2010.

[6] S. Singh, et al.,, " Application of SVC on IEEE 6 Bus System for Optimization of Voltage Stability," Indonesian Journal of Electrical Engineering and Informatics (IJEEI), vol. 3, pp. 1-6 March 2015.

[7] N. P. Padhy, et al., "A Hybrid Model for Optimal Power Flow Incorporating FACTS Devices," IEEE Power Engineering Society Winter Meeting, vol. 2, pp. 510-515, January 2001.

[8] M. I. Azim and M. F. Rahman, "Genetic Algorithm Based Reactive Power Management by SVC," International Journal of Electrical and Computer Engineering (IJECE), vol. 4, pp. 200-206, 2014.

[9] S. Ranganathan and M. Surya Kalavathi. M, "SVC Placement for Voltage Profile Enhancement Using Self Adaptive Firefly Algorithm," TELKOMNIKA Indonesian Journal of Electrical Engineering, vol. 12, pp. 59765984, 2014.

[10] T. S. Chung and Y. Z. Li, "A Hybrid GA Approach for OPF with Consideration of FACTS Devices," IEEE Power Engineering Review, 21(2), pp. 47-50, 2001.

[11] W. Shao and V. Vittal, "LP-Based OPF for Corrective FACTS Control to Relieve Overloads and Voltage Violations," IEEE Transaction on PWRS, 21(4), pp. 1832-1839, 2006.8

[12] K. Deb, et al., "A Fast and Elitist Multiobjective Genetic Algorithm: NSGA-II," IEEE Transactions on Evolutionary Computation, 6(2), pp. 182-197, April 2002.

[13] L. Qi., “AC System Stability Analysis and Assessment for Shipboard Power Systems”, PhD Theses, University of A \& M Texas, 2004. 
[14] D.Van Veldhuizen, "Multiobjective Evolutionary Algorithms: Classifications, Analyses, and New Innovations", Ph.D. thesis, Department of Electrical and Computer Engineering. Graduate School of Engineering. Air Force, 2011.

[15] F. Di Pierro, et al., “An Investigation on Preference Order Ranking Scheme for Multiobjective Evolutionary Optimization," IEEE Transactions on Evolutionary Computation, vol. 11, pp. 17-45, 2007.

[16] K. Deb and M. Goyal, "A Combined Genetic Adaptive Search (Geneas) for Engineering Design”, Computer Science and Informatics, 26(4), pp. 30-45, 1996.

[17] J. Dhillon, "Multi Objective Optimization of Power Dispatch Problem Using NSGA-II," Master Thesis, Thapar University, Patiala, July 2009.

[18] D. Murali, et al., "Comparison of FACTS Devices for Power System Stability Enhancement," International Journal of Computer Applications, Vol. 8., October 2010.

\section{BIOGRAPHIES OF AUTHORS}
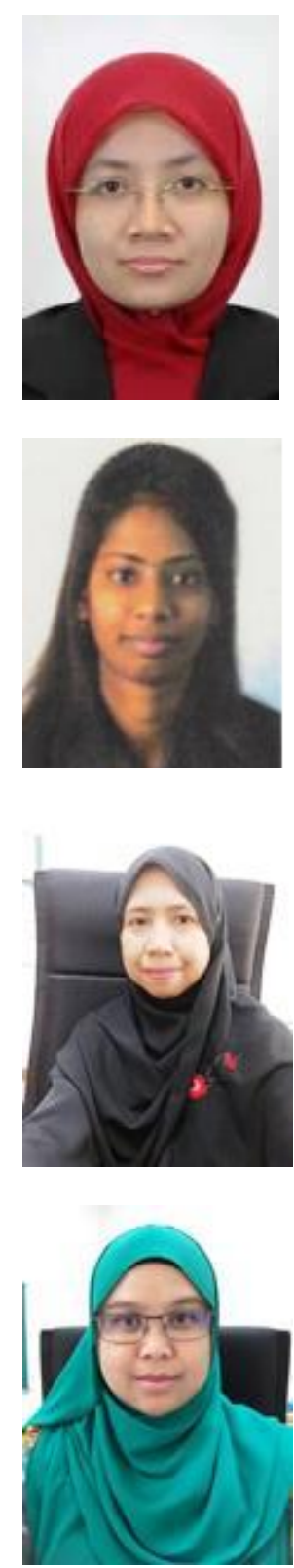

Nor Rul Hasma Abdullah obtained a Bachelor of Electrical Engineering (Hons) from Universiti Teknologi Malaysia in 2002, M.Eng in Electrical Engineering from Universiti Tun Hussein Onn Malaysia in 2004 and PhD in Electrical Engineering in 2012 from Universiti Teknologi MARA. Her research interest includes power system stability, optimization techniques, distributed generation, swarm optimization and meta-heuristic techniques. To date, she is currently a senior lecturer at Universiti Malaysia Pahang, Malaysia.

Mahaletchumi A/P Morgan obtained a Bachelor of Electrical \& Electronics Engineering (Hons) from University Malaysia Pahang (UMP) in 2014, M.Eng in Electrical Engineering (Power System) from University Malaysia Pahang (UMP) in 2017. Her research interest includes power system stability, optimization techniques especially Evolutionary Programming. Currently, she is working as an Assistant Manager at Telekom Malaysia, TM.

Mahfuzah Mustafa obtained Diploma in Electronics from Universiti Teknologi Malaysia in 1998. She received Bachelor of Engineering (Hons) in Computer System \& Communications from Universiti Putra Malaysia in 2002, then, she received Master of Electrical Engineering from Universiti Tun Hussein Onn Malaysia in 2004. Her Philosophy Doctor was received in 2015 from Universiti Teknologi MARA Malaysia in the field of Bio-signal EEG Analysis. Currently she is a Senior Lecturer at Faculty of Electrical and Electronics Engineering, Universiti Malaysia Pahang (UMP), Malaysia. Her current research interests include image/signal processing, bio-signal analysis, computer vision, biomedical engineering and artificial intelligence.

Rosdiyana Samad was born in Selangor, Malaysia in 1980. She received the BEng. in Electrical Engineering from the Kolej Universiti Teknologi Tun Hussein Onn (KUiTTHO), Johor, Malaysia in 2002. In 2005 she received MSc. in Electrival Engineering from Universiti Sains Malaysia (USM) in Penang, Malaysia. She received PhD degree in Engineering (Intelligent Mechanical Systems Engineering) from Kagawa University, Kagawa, Japan in 2012. Currently she is a Senior Lecturer at Faculty of Electrical and Electronics Engineering, Universiti Malaysia Pahang (UMP), Malaysia. Her current research interests include computer vision, image processing, pattern recognition, biomedical engineering, artificial intelligence and humancomputer interaction (HCI). 


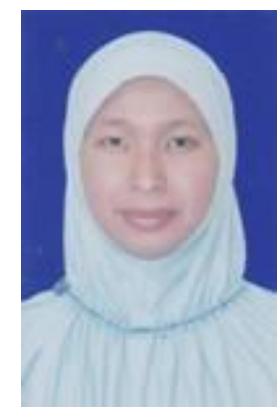

Dwi Pebrianti is a senior lecturer in Faculty of Electrical \& Electronics Engineering, University Malaysia Pahang, UMP, Malaysia since 2013. She received Bachelor of Engineering in electronics engineering from Universitas Indonesia, Indonesia, in 2001 and joined an oil gas company, Caltex Pacific Indonesia in the same year. She received Master of Engineering from the Department of Engineering Synthesis, The University of Tokyo, Japan in 2006. Her Philosophy Doctor was received in 2011 from Chiba University in the field of Artificial System Science. Since then, she was serving Chiba University as a Postdoctoral fellow in the same field. Her main works are including image processing for robot navigation, control theory for robot navigation, automation, control system, robotics, wearable computer, artificial intelligence, nonlinear system and control, Unmanned Aerial Vehicle, Motion \& dynamics control, embedded system design, Motion tracking system, Swarm robot and Optimization technique. 